\title{
Ruptures, éd. établie par Jean Galard
}

\section{Fatima Pilone}

\section{(2) OpenEdition}

\section{Journals}

\section{Edizione digitale}

URL: https://journals.openedition.org/studifrancesi/41457

DOI: 10.4000/studifrancesi.41457

ISSN: 2421-5856

\section{Editore}

Rosenberg \& Sellier

\section{Edizione cartacea}

Data di pubblicazione: 1 juillet 2004

Paginazione: 244

ISSN: 0039-2944

\section{Notizia bibliografica digitale}

Fatima Pilone, «Ruptures, éd. établie par Jean Galard», Studi Francesi [Online], 142 (XLVIII | I) | 2004, online dal 30 novembre 2015, consultato il 09 septembre 2021. URL: http://journals.openedition.org/ studifrancesi/41457 ; DOI: https://doi.org/10.4000/studifrancesi.41457

\section{Questo documento è stato generato automaticamente il 9 septembre 2021.}

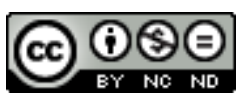

Studi Francesi è distribuita con Licenza Creative Commons Attribuzione - Non commerciale - Non opere derivate 4.0 Internazionale. 


\title{
Ruptures, éd. établie par Jean Galard
}

\author{
Fatima Pilone
}

\section{NOTIZIA}

AA. VV., Ruptures, éd. établie par Jean GALARD, Paris, École nationale supérieure des beaux-arts, Musée du Louvre, 2002, p. 368.

1 Ruptures. De la discontinuité dans la vie artistique è un testo nato sotto la direzione di Jean Galard (direttore del servizio culturale del Louvre sino al luglio 2002) ed è un insieme di saggi tratti dal colloquio tenutosi al Museo del Louvre (26 e 27 maggio 2000), in occasione dell'esposizione intitolata «L'Empire du Temps». La mostra nasceva dal tentativo di analizzare la discontinuità che segna la storia del legame tra Antichità e Occidente moderno e vedeva tutta una serie di opere molto antiche affiancate ad opere moderne e contemporanee.

2 La mostra, e con essa il colloquio, metteva in luce la dicotomia continuità-rottura, tipica della creazione artistica, secondo la quale la storia dell'arte è suddivisa in una serie di periodizzazioni, che contemplano un avant e un après. Secondo quanto scrive Galard nella prefazione al testo, il sapere umano, attraverso un procedimento di retrospezione, stabilisce rotture e continuità con le forme di conoscenza anteriori e, in questo caso, gli autori dei diversi saggi si sono soffermati sull'aspetto di rottura, rottura che diviene quindi un modo per interpretare la storia stessa del pensiero umano.

3 Nel primo saggio, «À la recherche du paradis perdu: les mappamondes du XIIIe siècle» di Alessandro Scafi, viene proposta l'utopica divisione di un paese in zone, ognuna a rappresentare un'epoca distinta. Perché utopica? Perché si porrebbe il problema di come tracciare i vari confini, ovvero quali rotture prendere in considerazione per segnare le diverse epoche. Queste rotture, infatti, sono stabilite dagli storici, sempre in base a quel fenomeno di retrospezione sopracitato. La prima, quella primordiale, è sancita dal peccato originale e dall'idea dell'esistenza di un Giardino dell'Eden, presente sulle carte geografiche del XIII secolo e studiate da Scafi. Il peccato di Adamo ed Eva segna una prima doppia rottura spazio-temporale, tipica della struttura doppia del 
Tempo cristiano. Questa rottura, definita da Scafi «inaugurale», è allo stesso tempo una promessa di salvezza, in visione di un paradiso che sarà ritrovato e, quindi, di una rupture guérie.

4 Con il saggio di Daniel Arasse, «Perspective régulière: rupture historique», l'attenzione si sposta nella Firenze del XV secolo, dove l'invenzione della «prospettiva regolare» segna nella pittura europea una rottura che l'autore definisce «storica», che influenza non solo le arti pittoriche, bensì l'intero modo di concepire la proporzione tra le forme e, di conseguenza, lo spazio.

5 Il saggio successivo di Michael F. Zimmermann, «Le jardin de Cosme I à Castello: réflexions sur le maniérisme et l'histoire de l'art», nasce ancora una volta dall'analisi di forme artistiche, per giungere poi ad estenderne il risultato ad altri ambiti della storia umana. Secondo l'autore il Manierismo, concetto creato nel XX secolo, segna un'ennesima rottura, non solo sul piano artistico, ma nella percezione del mondo e della conoscenza umana: è l'origine di una sensibilità «moderna», quella a portata dal nuovo potere ducale. È qui ben evidente come lo studio delle rotture artistiche possa svelare le rotture storiche, e viceversa.

6 Un'altra rottura «brutale» è quella presa in considerazione da Gabriele Bickendorf, in «Après Colbert: un divorce des sciences et des arts?». Egli ritiene che la morte di Colbert, avvenuta nel 1683, sancisca la morte anche di una campagna di «visualizzazione del sapere», in cui le scienze e le arti erano chiamate a cooperare in maniera unica: è il caso, ad esempio, della gravure, in cui ad elementi artistici erano affiancati elementi tipici del dominio tecnico-scientifico, come una sorta di spiegazione degli elementi artistici stessi.

Questi sono solo alcuni esempi degli interventi sul concetto di rottura. Altri saggi trattano di aspetti specifici di argomenti di più diffusa conoscenza, come in «De la théologie à l'anthropologie: le mythe au tournant des XVIIe et XVIIIe siècles en France» di Julie Boch e in «Temps de l'art et temps de l'histoire. Réflexions à partir de la Querelle des Anciens et des Modernes» di Jaqueline Lichtenstein, in cui la famosa Querelle viene vista come la nascita di un nuovo spirito filosofico, secondo il pensiero cartesiano del «commencer tout de nouveau».

Altri ancora trattano di aspetti ancor più specifici, come nel caso di Jann Matlock e del suo scritto «Olympia devient française, ou comment la modernitè a perdu la mémoire», dove l'analisi ruota attorno al conosciuto dipinto di Manet.

E ancora, altri autori sottolineano nuovamente lo stretto legame tra le rotture artistiche e quelle storiche, come Giorgio Muratore in «Des futuristes aux novécentistes», Celso Favaretto in "Modernité et nationalisme» e Abigail SolomonGodeau in «Maîtres anciens et maîtresses anciennes: le féminisme, l'histoire de l'art et l'épistémologie»: tre saggi in cui è evidente il nesso tra determinate nuove forme d'arte e nuovi processi storici, sociali e politici.

10 Lo studio più «attuale», quello riferito alle nuove forme artistiche sorte con l'avvento del computer, è ad opera di Martin Kemp e Nicholas Lambert: «L'art via l'ordinateur: un nouveau cru ou juste une nouvelle étiquette?».

11 Infine, quasi a riassumere quanto letto nelle molte pagine di questo testo, il saggio di Jacques Rancière, «Les énoncés de la rupture»: l'ennesima presa di coscienza che la storia dell'arte guarda a se stessa e alle altre discipline, come a tutti gli aspetti del 
sapere umano, attraverso un fenomeno di differenziazione, rilevando quindi non tanto la continuità con le forme preesistenti, quanto proprio ciò che di nuovo propone. 